\title{
Plasma Technology \& its Impact on Next Generation Smart Textile
}

\author{
Bornali Sarma* \\ Physics Division, VIT University, India \\ Submission: April 19, 2018; Published: May 14, 2018 \\ *Corresponding author: Bornali Sarma, Physics Division, VIT University, Chennai-600127, India, Email: bornali.sarma@vit.ac.in
}

Abstract

Eco-friendly plasma pretreatment can be introduced on any fabric to enhance the surface properties and adhesion of Graphene Oxide (GO) in order to fabricate electronic smart textile. Next generation fashion technology is bound to offer comfort level in all wearable cloths, be it is related to health, defense or space technology sector.

Keywords: Smart textile; Plasma technology; Graphene; Adhesion

Abbreviations: GO: Graphene Oxide; DBD: Dielectric Barrier Discharge; DLC: Diamond-Like Carbon

\section{Introduction}

Recently the electro conductive textiles are gaining a lot of attention due to its low cost, availability, light weight, flexibility, and wearer comfort. However, conductivity is required to transfer the electrical signals to or from textile materials. The textile material which exhibits electrical conductivity is called electronic-textiles (e-textiles). Various methods are available to integrate electrical conductivity to the fabrics. The manufacture of textiles provides an economic boost to many countries in the world. Cotton is a natural cellulose fiber in the textile industry and also biodegradable and eco-friendly. Cotton fabric is soft and skin friendliness for the wearer. The cost of the cotton fabric is low when it's compared to other textile materials. The cotton fabric is electrically insulator which limits the application in various fields. Many researchers have fabricated natural fabrics into electrically conductive fabrics by deposition of metals, metal oxide, carbon-related derivatives and conducting polymers on the surface of the fabrics. Especially the utilization of graphene is a promising material for two-dimensional sheets to create conductive fabrics for smart textiles. It has gained more attention to the textile material due to mechanical, thermal, optical and electrical properties. The graphene functional finishing fabrics are attracted by the wearers. Various methods have been available for the synthesis of graphene and its derivatives. Modified Hummers method is cheap and it is a large scale production method to synthesize Graphene Oxide (GO). However, a reduction step is required to convert GO into RGO. It is difficult to improve the adhesion between GO and the surface of the fabrics due to hydrophobic nature of grey cotton fabrics.
Grey cotton fabric is not a processed one and it is not undergone any kind of pre-treatments or any chemical finishes. Hence this fabric is hydrophobic in nature. It is very important to convert hydrophobic into hydrophilic before any kind of coatings. To overcome this challenge by physical or chemical pre-treatments on fabrics, this improves the wettability and adhesion of the surfaces. Generally textile industries are using conventional wet chemical methods for surface modifications. The wet chemical process are increasingly replaced by plasma treatment in terms of reduction of energy, time, water and single step dry clean process, no toxic fumes or waste product generated and many functionalities like hydrophilic or hydrophobic, wettability dyeability can be imparted on the fabrics based on the plasma gases.

Plasma technology is an eco-friendly technique to modify the surface of the textile fabrics and increase the adhesion of the deposit materials. Plasmatreatment improves the surface without changing the bulk properties of the material. So far, the plasma treatment has improved the dyeing, hydrophobic, hydrophilic, wicking, colour fastness, pill resistance etc. Pre-treatment of viscose and cotton fibre using air, nitrogen, and oxygen, and also DBD (Dielectric Barrier Discharge) plasma treatment showed improvement in the sorption of silver from aqueous solution. Improvement in the wettability by using a coating of DiamondLike Carbon (DLC) film on plasma treated cotton fabrics can be achieved. Enhancement in the UV- protection and antibacterial activity of cellulose-containing fabrics by using oxygen plasma pre-treatment followed by $\mathrm{Cu}$ - acetate or $\mathrm{Zn}$ - acetate treatment 
is also reported. Coated titanium dioxide on oxygen plasma pretreated cotton fabrics to improve flame retardant properties is under investigation.

The oxygen plasma treatment on the fabrics produces radicals, functional groups, and it increases the roughness due to ion bombardment on the surface of the fabrics. The roughness increases the good contact of the fabrics which enhances the adhesion of the deposition materials.

\section{Conclusion}

Plasma pretreatment of the textile fabrics for enhancing the adhesivity of any type of coating is gaining more popularity nowadays due to its environment friendly, economic, less time \& energy consumption and easy to operate features. So, coming decades are looking forward for more \& more involvement of plasma technology into the textile and fashion industry.

\section{Acknowledgement}

I like to acknowledge K. Vinisha Rani, my research student for her involvement in the present work.

Your next submission with Juniper Publishers
will reach you the below assets
- Quality Editorial service
- Swift Peer Review
- Reprints availability
- E-prints Service
- Manuscript Podcast for convenient understanding
- Global attainment for your research
- Manuscript accessibility in different formats
( Pdf, E-pub, Full Text, Audio)
- Unceasing customer service
Track the below URL for one-step submission
https://juniperpublishers.com/online-submission.php

